Article

\title{
Effect of Transition Layer on Properties of Tungsten-Tantalum (W-Ta) Laminated Composite
}

\author{
Zizhi Yan, Gaoyong $\mathrm{Xu}$ and Jinping Suo * \\ State Key Laboratory of Material Processing and Die \& Mould Technology, School of Materials Science and \\ Engineering, Huazhong University of Science and Technology, Wuhan 430074, China; \\ yanzizhi@hust.edu.cn (Z.Y.); 18107210396@163.com (G.X.) \\ * Correspondence: jinpingsuo@hust.edu.cn; Tel.: +86-1898-617-1729
}

Received: 25 March 2020; Accepted: 24 April 2020; Published: 26 April 2020

\begin{abstract}
Tungsten has many attractive properties, but its brittleness limits its application. Our team has found that the brittleness of tungsten can be greatly improved by combining the brittle tungsten with tantalum. Furthermore, we found that if a suitable transition layer is added between tungsten and tantalum, the properties of the composite will be further improved. In this paper, we studied the effect of different transition layers on the properties of W-Ta laminated composite to explore a suitable transition layer, which can effectively improve the toughness of the composite and solve the problem of tungsten application. We have prepared four kinds of W-Ta laminated composites with $\mathrm{Ni}, \mathrm{Ti}, \mathrm{Nb}$, and $\mathrm{Mo}$ as transition layers. Ta-W laminated composites were prepared by stacking layers with Ta, transition layer, $\mathrm{W}$ alternately and sintered by spark plasma sintering (SPS). The tensile and three-point bending tests were carried to compare the mechanical properties. The tensile fracture morphology and three-point bending crack distribution were observed by SEM. In addition, the diffusion of elements in the transition layer and the influence of element diffusion on the tungsten structure were also studied to clarify the toughening mechanism. The results show that $\mathrm{Nb}$ is a satisfying transition layer, which not only improves the strength of $\mathrm{W}$-Ta laminated composite, but also improves the toughness. The tensile test of $\mathrm{W} / \mathrm{Nb} / \mathrm{Ta}$ laminated composite shows a typical plastic fracture mode with an elongation of $13 \%$. Three-point bending test also shows high strength and good toughness. In addition, Voigt model was used to predict the elastic modulus of W-Ta laminated composites and compared with the experimental results.
\end{abstract}

Keywords: tungsten laminated composite; transition layer; layered toughening; interface

\section{Introduction}

Tungsten has many excellent properties, e.g., a high melting point $\left(3422{ }^{\circ} \mathrm{C}\right)$, high thermal conductivity, good mechanical properties in high temperature and low thermal expansion coefficient, which make it very suitable for high heat flux components and extreme environment applications including plasma facing materials (PFMs) in fusion reactors or rocket nozzles in space applications [1-4]. However, pure tungsten and tungsten alloys are known to be brittle at room temperature and have high ductile-to-brittle transition temperatures (DBTT) which extremely restrict its application. Improving the ductility of tungsten can have significant impact on both the manufacturing and application range of tungsten [5]. Although there is mass of reported research on improving the ductility of tungsten, it remains a difficult challenge [6-8].

In order to overcome the brittleness of tungsten at room temperature, three main methods have been widely investigated, alloying, tailoring the microstructure and forming tungsten composites [9]. In the 1950s, G. Geach et al. [10] alloyed tungsten with rhenium and achieved a dramatically improvement of the ductility. Adding Re to W can increase the stability of grain structure, increase the creep strength 
and limit the recrystallization. The addition of Re will not only enhance the high temperature strength and plasticity of the material, but also improve its brittleness at low temperature. However, as we known, rhenium is a high cost rare element, making these alloys prohibitively expensive for many applications [2]. Many researchers tried to replace rhenium with tantalum [11] vanadium [11,12], titanium [13], or other elements to accomplish similar results. However, there is little experimental evidence for the effectiveness of other alloying elements.

There are also many researches improving the toughness of tungsten via the second way by tailoring the microstructure of tungsten and its alloy. It is found that thermomechanical treatment, such as hot rolling, hot forging, and hot pressing, can significantly improve the brittleness of $\mathrm{W}$ and reduce its DBTT. Yan, Q.Z et al. [14] reduced the DBTT to about $450{ }^{\circ} \mathrm{C}$ by hot rolling W-La $\mathrm{O}_{3}$ alloy. Battabyal. $\mathrm{M}$ et al. [15] decreased the DBTT of $\mathrm{W}-\mathrm{Y}_{2} \mathrm{O}_{3}$ alloy to about $400{ }^{\circ} \mathrm{C}$ by hot forging. Recrystallized ultra-fine grained $\mathrm{W}$-TiC was prepared by $\mathrm{H}$. Kurishita et al. [16] and DBTT was found to be as high as $830 \mathrm{~K}$. Hot pressing under the condition of extremely low oxygen content, the DBTT of $\mathrm{W}$-TiC reduced to $240 \mathrm{~K}$, and its thermal shock resistance has also been improved. At present, thermomechanical treatment is an effective method to improve the brittleness of W material, but its DBTT is still up to several hundred degrees Celsius and the material is susceptible to the effect of thermal shock. Rolling below recrystallization temperature can get ultrafine grain and reduce the DBTT of tungsten from above $700{ }^{\circ} \mathrm{C}$ to less than $300{ }^{\circ} \mathrm{C}[17,18]$. Ultrafine-grained tungsten (with a diameter of about $300 \mathrm{~nm}$ ) alloys also have been produced by high pressure torsion and showed increased fracture toughness at room temperature [19]. Reiser, J et al. [20] reported that severely deformed tungsten foil is ductile at room temperature in the as-deformed state. However, both texture and dislocations generated by rolling at low temperature or other methods will gradually disappear during high temperature annealing, resulting in an increase in DBTT [21,22].

In addition to alloying and tailoring the microstructure, strengthening methods also involve structure optimization designs addressing toughening such as composite forming. At present, fiber toughening and laminar toughening have attracted wide attention due to their obvious toughening effect in ceramic matrix composites (CMC). Juan Du et al. [23] toughened tungsten with tungsten fiber exploiting the toughness of tungsten fiber itself and the energy absorption related to the crack deflection and friction sliding at the interface. The results showed that the good interface between the fiber and matrix could improve the fracture toughness and shear strength significantly, but the interface optimization and thermal stability of the system needed further study. The method of laminar toughening is often used in ceramic phase toughening. It has better toughening effect in theory than fiber toughening [24]. Jens Reiser et al. [25] brazed many pieces of tungsten foil with AgCu solder and successfully prepared tubular and laminate materials. The test results showed that the DBTT of the material was significantly lower than that of pure tungsten and has better toughness. This shows that the laminar composite forming is a viable way of tungsten toughening.

Many reports have shown that forming tungsten composites such as W-Ta, W-Ti, W-V, W-Cu can obviously improve toughness of tungsten in both high and low temperature. However, it brings another problem of strong inter-diffusion in the long-term high temperature environment [22], which will weaken the interface and decrease the strength of laminate composites. Therefore, some fundamental problems should be researched about inter-diffusion between tungsten and the ductile metals used in the composite formulation. Laminated tungsten-based composites have been studied by many researchers in recent years. Tungsten has similar properties with ceramics, but better thermal conductivity than most of them. Moreover, many metals, such as Ta, V, Nb, Mo, Ti, Re, etc., can form solid solution with tungsten, and Re is the most effective element to improve mechanical property of tungsten so far [2]. This means that these metals are capable to bond with $\mathrm{W}$ well.

Our team has been previously researching laminated W/Ta system for several years [26,27]. We found that Ta has a good toughening effect on W. Moreover, when a TiN transition layer is added between tungsten and tantalum. The W/TiN/Ta laminated composite has much higher strength than $\mathrm{W} / \mathrm{Ta}$, but the ductility decreased. Hard TiN coating, which separated the hard W and soft Ta layer, 
makes the composite stronger but hard brittle. These results indicate that the transition layer has great effect on properties of W/Ta laminated composite. However, multiple-phase tungsten-based laminated composites are rarely reported, and the mechanism of increasing toughness by transition ceramics and metals is not explained clearly. Furthermore, the already mentioned problem, inter-diffusion in the long-term high temperature applications is still not solved for the laminar toughened tungsten composites. In this work, four kinds of $\mathrm{W}$-Ta laminated composites with different transition layers were prepared by spark plasma sintering (SPS). The tensile and three-point bending properties of these laminated composites were tested. The toughening mechanism of transition layer was studied by SEM and EDS. It is expected to clarify the toughening mechanism of the transition layer and find a suitable transition layer to prepare a tungsten laminated composite with high strength and good plasticity.

\section{Experiment}

\subsection{Preparation of Samples}

In this work, $\mathrm{Ni}, \mathrm{Ti}, \mathrm{Nb}$ and $\mathrm{Mo}$ films were selected as the transition layer of $\mathrm{W}$-Ta laminated composite. The Ta and $\mathrm{W}$ sheets were purchased from TianshengTai Pioneer Metals Corporation, Baoji, China. Ta was treated by cold rolling and vacuum annealing at $900-1100{ }^{\circ} \mathrm{C}$ for $1 \mathrm{~h}$ and furnace cooled to room temperature. W was treated by warm rolling and vacuum annealing at $900^{\circ} \mathrm{C}$ for $1 \mathrm{~h}$ and furnace cooled. Ni, Ti, Nb and Mo films were provided by Renxin Metal Materials Co., Ltd, Qinghe, China. Table 1 summarize the vendor specifications and physical properties of the matrix and different transition layers. Limited by the supplier, we are unable to purchase different transition layers of the same thickness. We used $30 \mu \mathrm{m}$ Ti transition layer to carry out the same experiment. It is found that the results are similar to those of $10 \mu \mathrm{m}$ Ti transition layer. Moreover, this paper focuses on the effects of the characteristics of the transition layer, such as element diffusion and interface bonding, on the W-Ta laminated composite. Therefore, in this paper, the author thinks that the thickness of the transition layer can be ignored.

Table 1. The vendor specifications and properties of matrix and different transition layers.

\begin{tabular}{cccc}
\hline Materials & Thickness & Purity & Melt Point \\
\hline $\mathrm{W}$ & $100 \mu \mathrm{m}$ & $99.95 \%$ & $3422^{\circ} \mathrm{C}$ \\
$\mathrm{Ta}$ & $100 \mu \mathrm{m}$ & $99.95 \%$ & $3017^{\circ} \mathrm{C}$ \\
$\mathrm{Ni}$ & $10 \mu \mathrm{m}$ & $99.99 \%$ & $1453^{\circ} \mathrm{C}$ \\
$\mathrm{Ti}$ & $10 \mu \mathrm{m}$ & $99.99 \%$ & $1668^{\circ} \mathrm{C}$ \\
$\mathrm{Nb}$ & $25 \mu \mathrm{m}$ & $99.99 \%$ & $2469^{\circ} \mathrm{C}$ \\
$\mathrm{Mo}$ & $15 \mu \mathrm{m}$ & $99.99 \%$ & $2620^{\circ} \mathrm{C}$ \\
\hline
\end{tabular}

In this work, several W-Ta laminated composites were prepared by SPS. Before SPS, W sheet was cut into $30 \mathrm{~mm}$ diameter discs by wire cutting. Others were cut into $30 \mathrm{~mm}$ diameter discs with scissors. Then, all the materials were cleaned by ultrasonic wave of acetone and alcohol for $5 \mathrm{~min}$, respectively, to remove the surface oil and other impurities and then dried in a vacuum drying box. Then, we alternately stacked Ta-T-W-T-Ta ... Ta (T means transition layer). The maximum thickness of the tensile specimen clamp we prepared is $1.6 \mathrm{~mm}$. Therefore, the stack thickness of tensile specimen is about $1.5 \mathrm{~mm}$. The design dimension of three-point bending specimen is $18(\mathrm{l}) \times 2(\mathrm{w}) \times 2(\mathrm{~h}) \mathrm{mm}$. Therefore, the stack thickness of three-point bending specimen is about $2 \mathrm{~mm}$. Then, the different $\mathrm{W}$-Ta laminated composites were sintered by SPS. Since the melting point of the transition layer is different. If $\mathrm{W}$-Ta of different transition layers is sintered at the same temperature. The transition layer with higher melting point may not be connected. The transition layer with a lower melting point may melt. According to our previous experience and the melting point of the transition layer, we have specified different sintering temperature of different W-Ta laminated composites. Table 2 shows the SPS conditions of different W-Ta laminated composites. 
Table 2. The SPS conditions of different W-Ta laminates.

\begin{tabular}{cccc}
\hline Composites & SPS Temperature & Pressure & Holding Time \\
\hline $\mathrm{W} / \mathrm{Ta}$ & $1700^{\circ} \mathrm{C}$ & $60 \mathrm{MPa}$ & $10 \mathrm{~min}$ \\
$\mathrm{~W} / \mathrm{Ni} / \mathrm{Ta}$ & $1000^{\circ} \mathrm{C}$ & $60 \mathrm{MPa}$ & $10 \mathrm{~min}$ \\
$\mathrm{~W} / \mathrm{Ti} / \mathrm{Ta}$ & $1200^{\circ} \mathrm{C}$ & $60 \mathrm{MPa}$ & $10 \mathrm{~min}$ \\
$\mathrm{~W} / \mathrm{Nb} / \mathrm{Ta}$ & $1500^{\circ} \mathrm{C}$ & $60 \mathrm{MPa}$ & $10 \mathrm{~min}$ \\
$\mathrm{~W} / \mathrm{Mo} / \mathrm{Ta}$ & $1500^{\circ} \mathrm{C}$ & $60 \mathrm{MPa}$ & $10 \mathrm{~min}$ \\
\hline
\end{tabular}

\subsection{Tensile Tests}

The sintered discs with diameter of $30 \mathrm{~mm}$ and thickness of $1.5 \mathrm{~mm}$ were cut into tensile samples by wire cutting for tensile tests. The dimension of the standard distance part of tensile specimen was about $12 \mathrm{~mm} \times 2.5 \mathrm{~mm} \times 1.5 \mathrm{~mm}$. The tensile specimen sketch is shown in Figure 1 . Tensile tests were conducted by Zwick/Roell Z020 universal testing machine with a speed of $1 \mathrm{~mm} / \mathrm{min}$ at room temperature. Load-displacement curves were obtained by the sensor and computer of the testing machine.

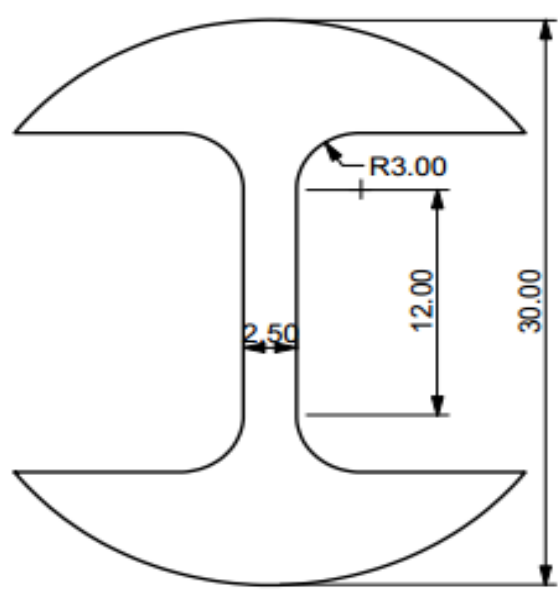

Figure 1. Schematic diagram of tensile sample and the thickness is $1.5 \mathrm{~mm}$.

\subsection{Three-Point Bending Tests}

The sintered discs with diameter of $30 \mathrm{~mm}$ and thickness of $2 \mathrm{~mm}$ were cut into three-point bending samples by wire cutting for three-point bending tests. Three-point bending tests were performed in the same test device as used for the tensile tests described above. Tests were conducted at room temperature, using a cross head speed of $2 \mathrm{~mm} / \mathrm{min}$. The sample size was about $18(\mathrm{l}) \times 2(\mathrm{w}) \times 2(\mathrm{~h}) \mathrm{mm}$, the testing span was $14 \mathrm{~mm}$. Sketch of three-point bending test is shown in Figure 2. Load-deformation curves were obtained by the sensor and computer of the testing machine. The three-point bending stress is calculated by the following Equation (1):

$$
\sigma=3 \mathrm{PL} /\left(2 \mathrm{bh}^{2}\right),
$$

where $\sigma$ is stress, MPa, P is load, N. L is span, $\mathrm{mm}, \mathrm{b}$ is sample width, $\mathrm{mm}$, and $\mathrm{h}$ is height, $\mathrm{mm}$. In order to observe the distribution of cracks, the cross section of the three-point bending specimen was sanded and polished, and the three-point bending test was terminated in advance. The crack distribution was then observed by Scanning Electron Microscope (SEM). 


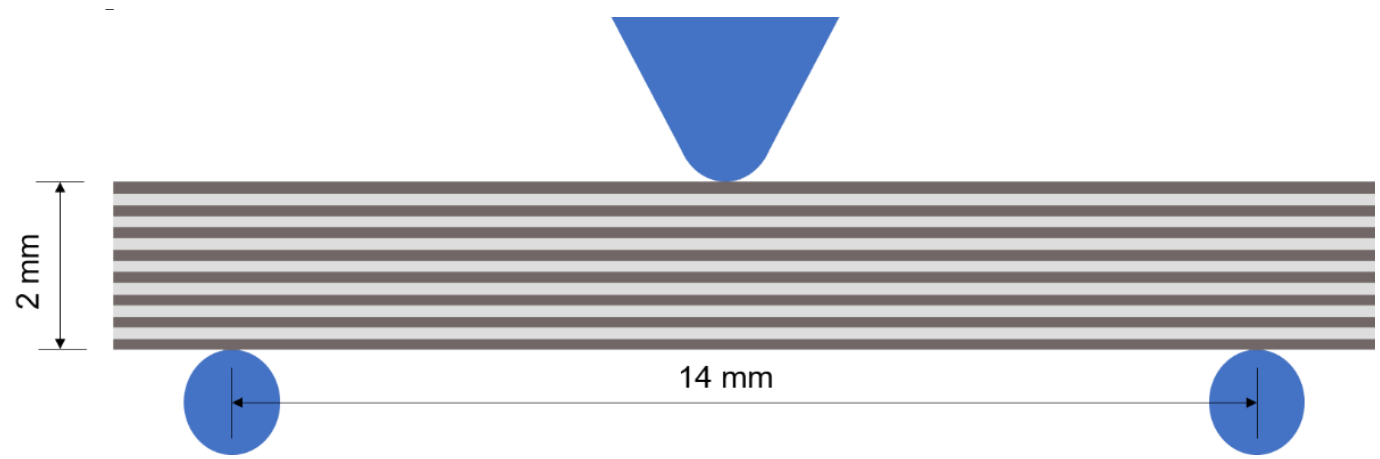

Figure 2. Schematic diagram of three-point bending test. The testing span is $14 \mathrm{~mm}$ and the height and width are $2 \mathrm{~mm}$.

\section{Results and Discussion}

\subsection{Tensile Test Results and Fracture Morphology}

Tensile test strain-stress curves of W-Ta laminated composite with different transition layers are shown in Figure 3. From the results, it can be found that the Ni, Ti, and Mo transition layers can only improve the strength of the laminated composite, but not the toughness. The fracture mode is brittle fracture. It is notable that the $\mathrm{W} / \mathrm{Nb} / \mathrm{Ta}$ has a great ductility. It has a lower strength, but its ductility is much higher than W/Ta. It exhibits ductile fracture model with a maximum elongation of $13 \%$. Table 3 is the strength and integral (integral of strength and plasticity) of varies W-Ta laminated composite. It can clearly be found that $\mathrm{Nb}$ has a great enhancement on the ductility of $\mathrm{W}$-Ta laminated composite.

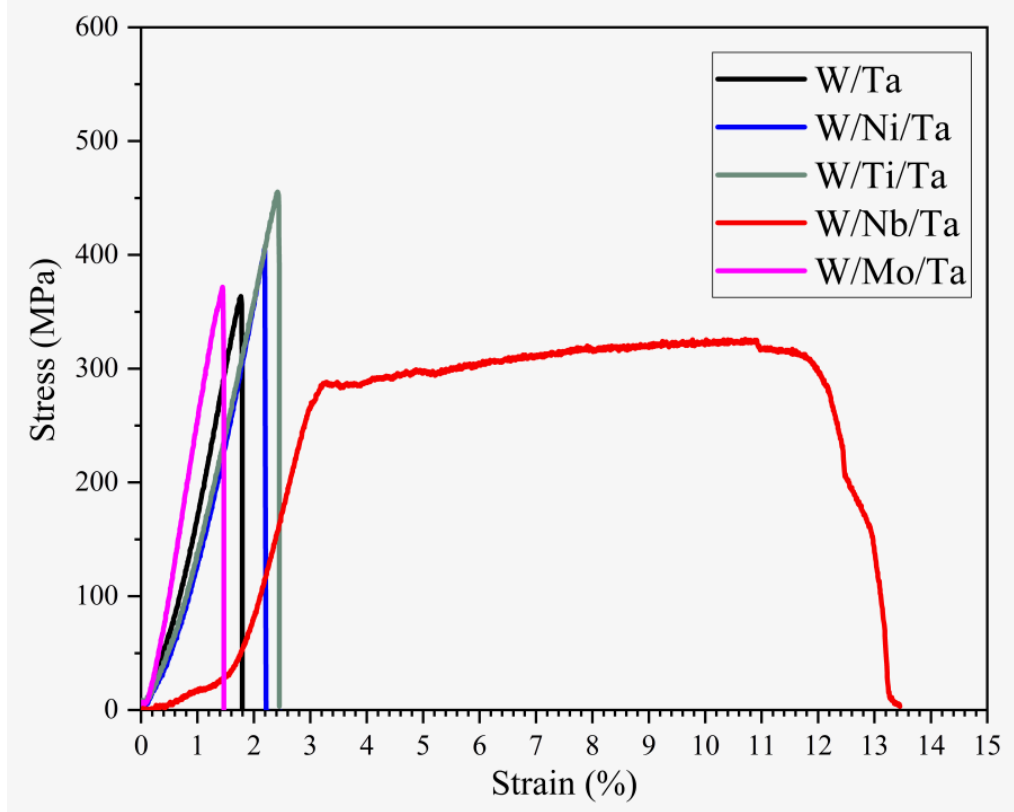

Figure 3. Tensile test strain-stress curves of W-Ta laminates with different transition layers.

Table 3. The strength and the integral of varies $\mathrm{W}$-Ta laminates.

\begin{tabular}{cccc}
\hline Composites & Strength $\mathbf{( M P a )}$ & Elongation $\mathbf{( \% )}$ & Integral $(\mathbf{M P a} \cdot \%)$ \\
\hline $\mathrm{W} / \mathrm{Ta}$ & 363 & 1.8 & 288 \\
$\mathrm{~W} / \mathrm{Ni} / \mathrm{Ta}$ & 405 & 2.2 & 366 \\
$\mathrm{~W} / \mathrm{Ti} / \mathrm{Ta}$ & 455 & 2.4 & 489 \\
$\mathrm{~W} / \mathrm{Mo} / \mathrm{Ta}$ & 372 & 1.4 & 258 \\
$\mathrm{~W} / \mathrm{Nb} / \mathrm{Ta}$ & 326 & 13 & 3236 \\
\hline
\end{tabular}


Fracture morphology of tensile specimens were then observed by SEM. Figure 4a shows the fracture morphology of W/Ta without transition layer and Figure $4 \mathrm{~b}$ shows its magnified view. We can see the tear ridge of Ta layer for its plastic deformation. It indicates that Ta has good toughening effect for its good plasticity. Figure $4 c, d$ shows the fracture morphology of W/Ni/Ta. As the sintering temperature of $\mathrm{W} / \mathrm{Ni} / \mathrm{Ta}$ is only $1000{ }^{\circ} \mathrm{C}$, lower than the recrystallization temperature of $\mathrm{W}$. The $\mathrm{W}$ still maintains rolling grain structure. After crack germinated in tungsten, it propagated along the tungsten rolling direction, as shown by the arrow in Figure 4c. In Figure 4d, we can find that there are a lot of dimples in the Ni layer. This indicates that plastic deformation occurs in the Ni layer during interface debonding. However, the combination of $\mathrm{Ni}$ and $\mathrm{W}$ is poor. In Figure $4 \mathrm{~d}$, it can be observed that there is an obvious interface between W and Ni. Moreover, the W/Ni interface has de-bonded in some region, as shown in the image at the upper right corner of Figure $4 \mathrm{~d}$. On the other hand, Ni will diffuse with Ta to form a diffusion layer, which shows brittle fracture. We can observe the diffusion layer, which is marked as $\alpha$ in Figure 4 d. Figure 4e,f shows the fracture morphology of W/Ti/Ta. As the sintering temperature is $1200{ }^{\circ} \mathrm{C}$, lower than the recrystallization temperature of $\mathrm{W}$, the $\mathrm{W}$ in the middle remains the original rolling structure. This is same as W/Ni/Ta. However, the $\mathrm{W}$ on both sides is debris-like. We speculate that the $\mathrm{W}$ texture changed when Ti diffused into it.

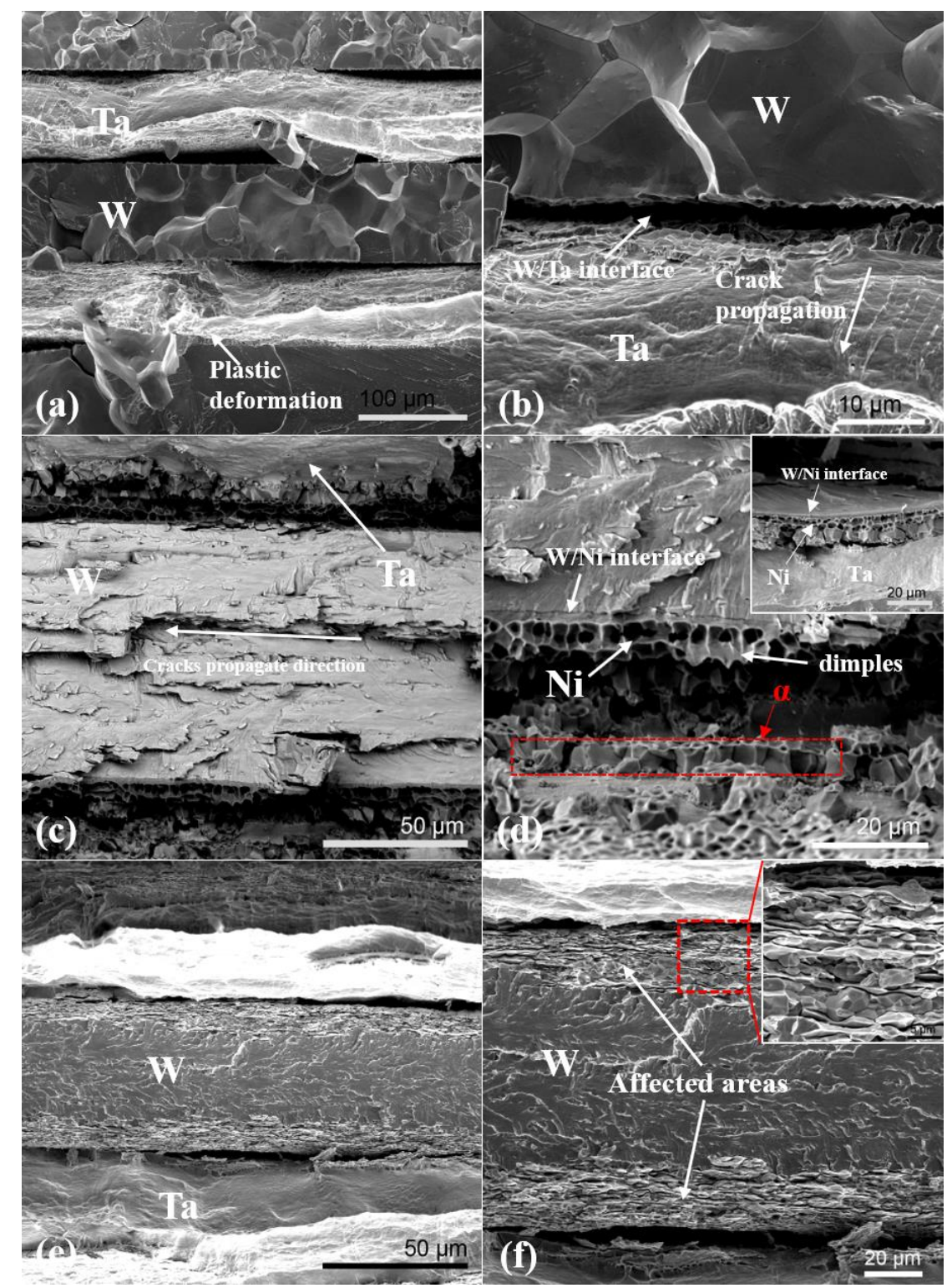

Figure 4. Tensile fracture morphology of $(\mathbf{a}, \mathbf{b}) \mathrm{W} / \mathrm{Ta},(\mathbf{c}, \mathbf{d}) \mathrm{W} / \mathrm{Ni} / \mathrm{Ta}$, and $(\mathbf{e}, \mathbf{f}) \mathrm{W} / \mathrm{Ti} / \mathrm{Ta}$ laminates. 
Figure $5 \mathrm{a}, \mathrm{b}$ shows the fracture morphology of $\mathrm{W} / \mathrm{Mo} / \mathrm{Ta}$. Figure $5 \mathrm{c}, \mathrm{d}$ shows the fracture morphology of $\mathrm{W} / \mathrm{Nb} / \mathrm{Ta}$. As the sintering temperature of $\mathrm{W} / \mathrm{Mo} / \mathrm{Ta}$ and $\mathrm{W} / \mathrm{Nb} / \mathrm{Ta}$ are both higher than the recrystallization temperature of $\mathrm{W}$, the $\mathrm{W}$ in $\mathrm{W} / \mathrm{Mo} / \mathrm{Ta}$ and $\mathrm{W} / \mathrm{Nb} / \mathrm{Ta}$ has the same texture as $\mathrm{W} / \mathrm{Ta}$ and shows a typical brittle fracture. The difference reflected on the bonding of interface and the inherent properties. For Mo transition layer, the bonding between $\mathrm{Mo} / \mathrm{W}$ is poor. The interface between $\mathrm{W}$ and Mo is mechanical binding. Mo transition layer cannot play a role in preventing crack propagation. We can see from Figure $5 b$ that after the cracks are generated in tungsten, it propagates to the interface. When encountering Mo layer, the cracks do not stop or deflect, and directly propagate into the Mo layer until Ta layer. Because of the poor plasticity of Mo, it also cannot weaken the crack tip stress. So, the $\mathrm{W} / \mathrm{Mo} / \mathrm{Ta}$ shows a poor property. $\mathrm{Nb}$ transition layer has a good bonding with both Ta and $\mathrm{W}$. The interface between $\mathrm{Ta}$ and $\mathrm{Nb}$ forms the reaction layer of several microns which enhances the toughness of interface highly. It can be seen from Figure $5 \mathrm{~d}$ that there are lots of dimples formed by plastic deformation in the reaction layer of $\mathrm{Ta}-\mathrm{Nb}$ interface. In addition, $\mathrm{Nb}$ has a good deflection effect on cracks. As shown in Figure $5 d$, the cracks generated in tungsten propagate through the interface to the $\mathrm{W}-\mathrm{Nb}$ reaction layer, and then to the $\mathrm{Nb}$ layer. Its propagation direction changes from vertical (vertical to the interface) to horizontal (horizontal to the interface). Additionally, $\mathrm{Nb}$ has a good plasticity, which can absorb the crack propagation energy through plastic deformation. The deflection of the crack propagation direction and the absorption of the crack propagation energy can prevent the further propagation of the cracks.

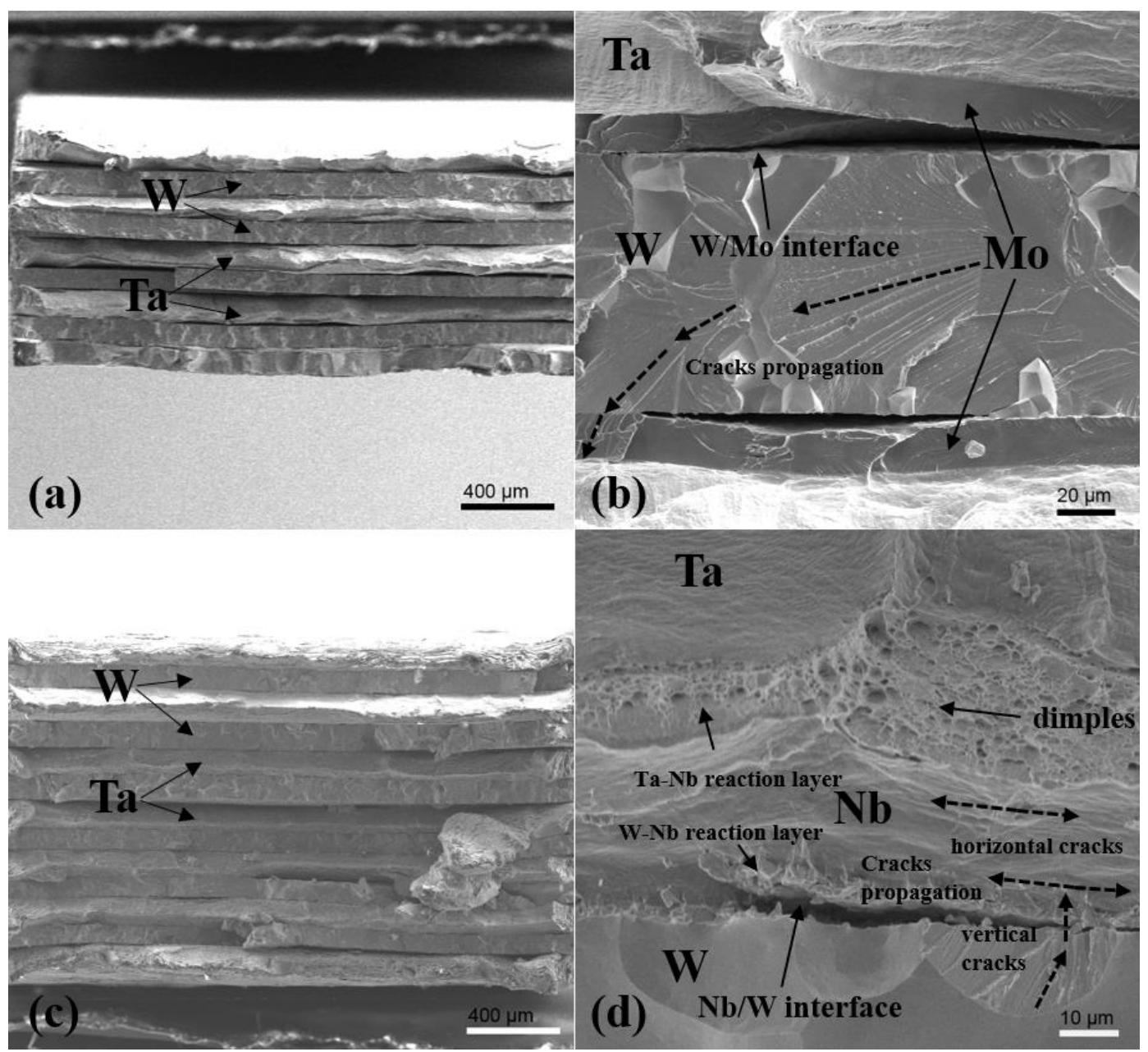

Figure 5. Tensile fracture morphology of $(\mathbf{a}, \mathbf{b}) \mathrm{W} / \mathrm{Mo} / \mathrm{Ta}$ and $(\mathbf{c}, \mathbf{d}) \mathrm{W} / \mathrm{Nb} / \mathrm{Ta}$ laminates. 
Furthermore, we observed the side morphology of $\mathrm{W} / \mathrm{Nb} / \mathrm{Ta}$ tensile specimen. Limited by the shape of tensile specimen, it is difficult to polish the side of specimen before tensile test. The preparation of the sample is to cut the portion near the fracture after the tensile fracture. Figure 6 shows the side morphology of $\mathrm{W} / \mathrm{Nb} / \mathrm{Ta}$ specimen after tensile fracture. It is clear from Figure 6a that there are many cracks in each $\mathrm{W}$ layer. That is to say, with the deformation of the composite, the brittle $\mathrm{W}$ layer cracks first. Because of the existence of niobium in the ductile layer, further crack growth is prevented. As the composite deforms further, more tungsten layers break, forming the morphology in Figure 6. Additionally, plastic deformation occurs in tantalum near each tungsten fractures. This makes $\mathrm{W} / \mathrm{Nb} / \mathrm{Ta}$ laminates show a very high plasticity.
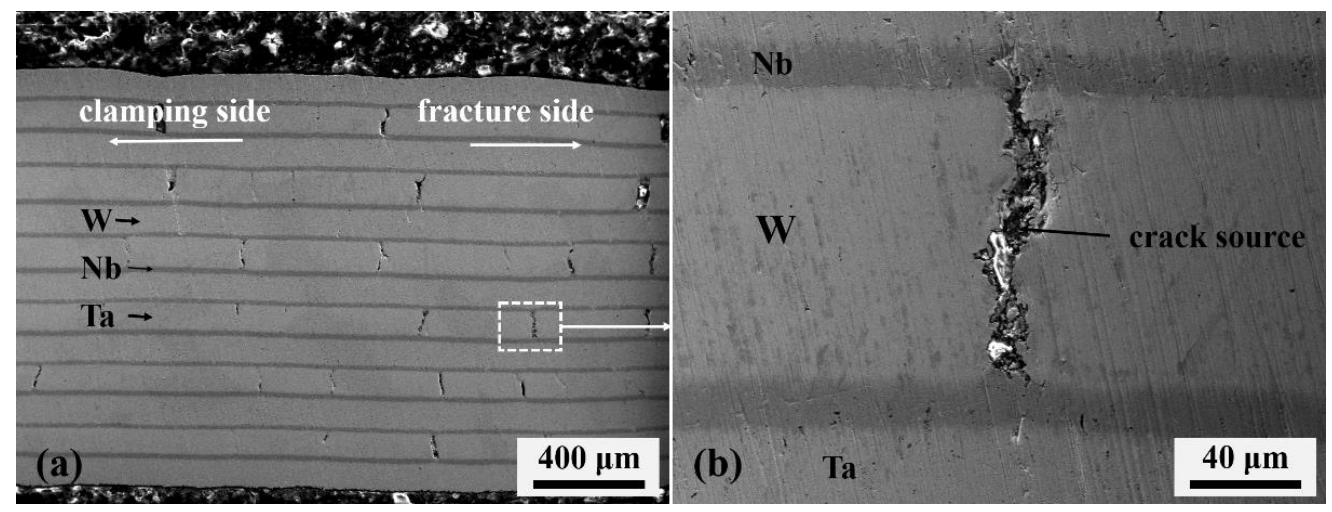

Figure 6. (a) The side morphology of $\mathrm{W} / \mathrm{Nb} / \mathrm{Ta}$ specimen after tensile fracture, (b) magnified views of W crack

\subsection{Three-Point Bending Test Results and Crack Distribution}

Figure 7 shows the stress-deformation curves of three-point bending of various W-Ta laminated composites with different transition layers. The results show that the Mo and $\mathrm{Nb}$ transition layers can improve the bending properties of $\mathrm{W}$-Ta laminated composites. These two transition layers maintain the same level of strength as W-Ta, but greatly increase the toughness. The Ni and Ti transition layer cannot effectively improve the performance of W-Ta laminated materials. Their fracture mode is the same as that of W-Ta.

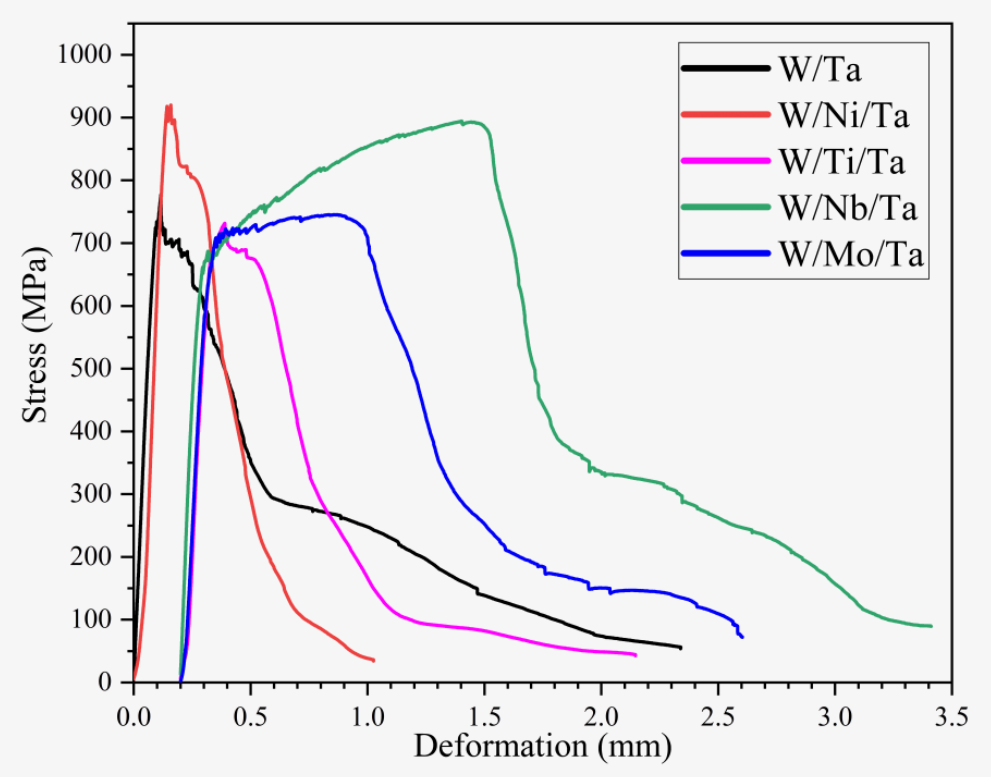

Figure 7. Stress-deformation curves of three-point bending of various W/Ta laminates with different transition layers. 
Figure 8 shows the crack distributions of various W/Ta laminated composites. We can find that there are three main toughening mechanisms of W-Ta laminated composites; (1) bridging effect of the ductile layer; (2) absorption of energy by plastic deformation of the ductile layer; (3) the deflection of the interface on the crack propagation direction. These three mechanisms are represented by $A, B$, and $\mathrm{C}$ in the figure. We can find that the plastic layer in $\mathrm{W} / \mathrm{Nb} / \mathrm{Ta}$ shows excellent bridging effect among these several kinds of laminated composites. A layer of tungsten can be broken in multiple places due to the bridging effect of the ductile layer. This results in more Ta layers being plastically deformed. In other words, more energy is absorbed. This also makes $\mathrm{W} / \mathrm{Nb} /$ Ta transition from unidirectional crack growth to multidirectional crack growth, as shown in Figure $8 \mathrm{~d}$ by the dotted arrows. Combining the above results, we can determine that $\mathrm{Nb}$ is a suitable transition layer. It can effectively improve the toughness of $\mathrm{W}$-Ta laminated composites.

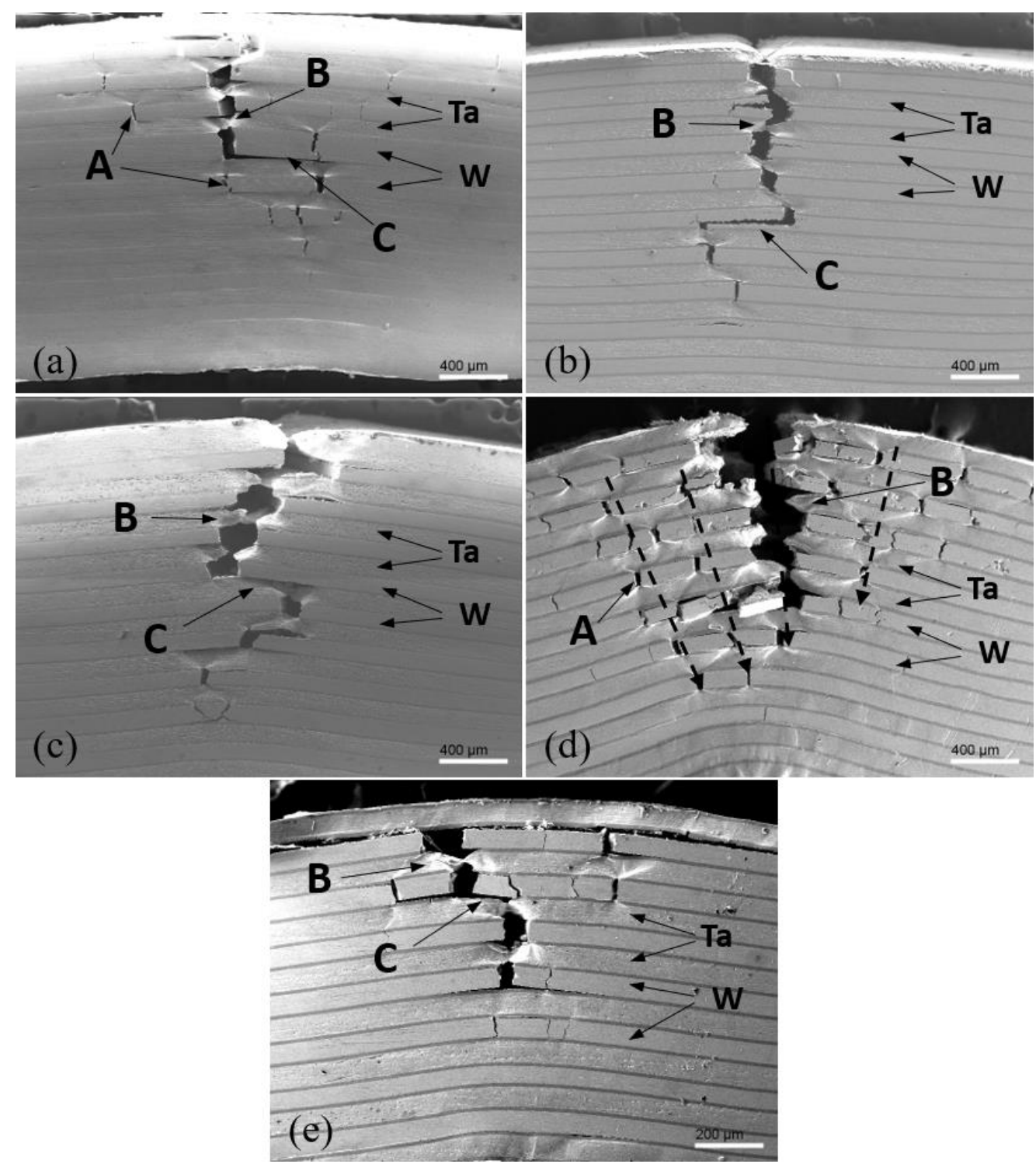

Figure 8. Crack distributions of various $\mathrm{W} / \mathrm{Ta}$ laminates with different transition layers, (a) W/Ta, (b) $\mathrm{W} / \mathrm{Ni} / \mathrm{Ta}$, (c) W/Ti/Ta, (d) W/Nb/Ta, (e) W/Mo/Ta.

\subsection{The Effect of Element Diffusion}

To verify the influence of transition layer diffusion on W-Ta laminated composite, surface scanning analyses of various W/Ta laminated composites were carried. Figure 9 shows the surface scanning 
analyses of various W-Ta laminated composite with different transition layers. From Figure $9 \mathrm{~b}$ we can find that a large amount of element diffusion occurs between $\mathrm{Ta}$ and $\mathrm{Ni}$ and form an interdiffusion zone. The interdiffusion zone can be observed in Figure $4 \mathrm{~d}$, which is marked by $\alpha$. Combined with the above results, we can confirm that the diffusion between $\mathrm{Ni}$ and $\mathrm{Ta}$ leads to the formation of brittle intermetallic compounds, which reduces the properties of W/Ni/Ta laminated composite. Figure 9c shows the surface scanning analyses of W/Ti/Ta. From it we can find that both Ta and W have diffused into Ti layer. The diffusion of Ta is large and the distribution of $\mathrm{Ta}$ in $\mathrm{Ti}$ is gradient along the diffusion direction. Due to the infinite solid solution between $\mathrm{Ta}$ and $\mathrm{Ti}$, they do not form brittle intermetallic compounds such as Ta-Ni. However, large elements diffusion worsen the properties of Ti and $\mathrm{W}$. Figure $9 \mathrm{~d}$ shows the the surface scanning analyse of $\mathrm{W} / \mathrm{Nb} / \mathrm{Ta}$. The $\mathrm{W}-\mathrm{Nb}$ and $\mathrm{Ta}-\mathrm{Nb}$ interface both form a reaction layer with a thickness of several microns by interdiffusion. These reaction layers are conducive to improving the strength and toughness of the interface, thereby improving the properties of the laminated composite. Figure 9e shows the surface scanning analyses of W/Mo/Ta. As can be seen from the figures, Mo has hardly any diffusion with Ta and W. From the previous experiment, we can know that there is a bad combination of the interface of W/Mo. W/Mo interface is easy to peel off during sample preparation. By comparing the surface scanning analyses images of $\mathrm{W} / \mathrm{Nb} / \mathrm{Ta}$ and $\mathrm{W} / \mathrm{Mo} / \mathrm{Ta}$, we can conclude that the proper element diffusion can form a reaction layer near the interface, which is conducive to improving the toughness of the interface. Of course, there is a premise that element diffusion cannot affect the matrix materials.

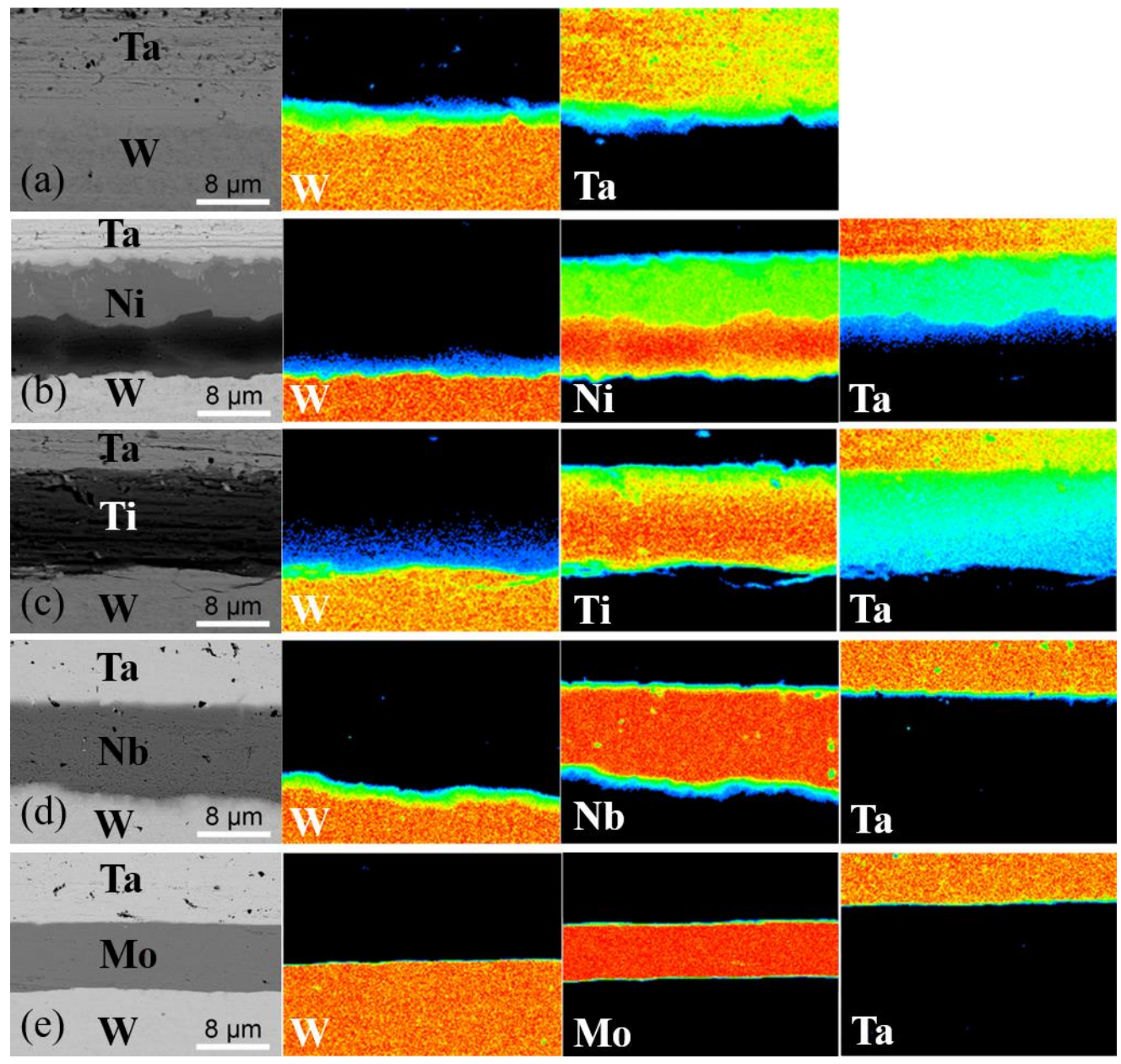

Figure 9. The surface scanning analyses of various $\mathrm{W} / \mathrm{Ta}$ laminates with different transition layers, (a) W/Ta, (b) W/Ni/Ta, (c) W/Ti/Ta, (d) W/Nb/Ta, (e) W/Mo/Ta. 
We further studied the $\mathrm{W}$ grain structure to verify the effect of element diffusion. Figure $10 \mathrm{~b}-\mathrm{f}$ shows the Back Scattered Electron (BSE) images of W grain with the effect of different transition layers and (a) is the original pure W without SPS. Since there is no diffusion between W and Mo, we did not prepare W/Mo/Ta samples. It can be found that although the original tungsten has been annealed, its grains are still a thin and strip rolled structure. From Figure $10 \mathrm{~b}$ we can find that the diffusion between $\mathrm{Ni}$ and $\mathrm{W}$ has changed the texture of $\mathrm{W}$. As the SPS temperature of $\mathrm{W} / \mathrm{Ni} / \mathrm{Ta}$ is lower than the recrystallization temperature of $\mathrm{W}$, the $\mathrm{W}$ in the middle remains the fine grains. However, the $\mathrm{W}$ grains near the interface are very coarse. The diffusion of $\mathrm{Ni}$ into tungsten causes the growth of $\mathrm{W}$ grains below the recrystallization temperature. This leads to the inhomogeneity of tungsten properties, which makes the crack propagate along the tungsten interior. W/Ti/Ta is opposite to W/Ni/Ta. From Figure 10c we can find that the $\mathrm{W}$ in the middle remains the original rolling structure, which is the same as that of $\mathrm{W} / \mathrm{Ni} / \mathrm{Ta}$. However, the $\mathrm{W}$ grains near the interface are very small. From the magnified view in Figure $10 \mathrm{~d}$ we can find that the closer to the edge of $\mathrm{W}$, the finer the $\mathrm{W}$ grains. However, these fine $\mathrm{W}$ grains are harm to the property of $\mathrm{W}$. It can be seen from Figure $4 \mathrm{f}$ that the fine grains have poor intergranular bonding and are clastic in fracture. For $\mathrm{W} / \mathrm{Nb} / \mathrm{Ta}$ and $\mathrm{W} / \mathrm{Ta}$, the SPS temperature is higher than the recrystallization temperature of tungsten, and the diffusion of transition layer elements does not affect the texture of $\mathrm{W}$. The $\mathrm{W}$ grains are coarse equiaxed.

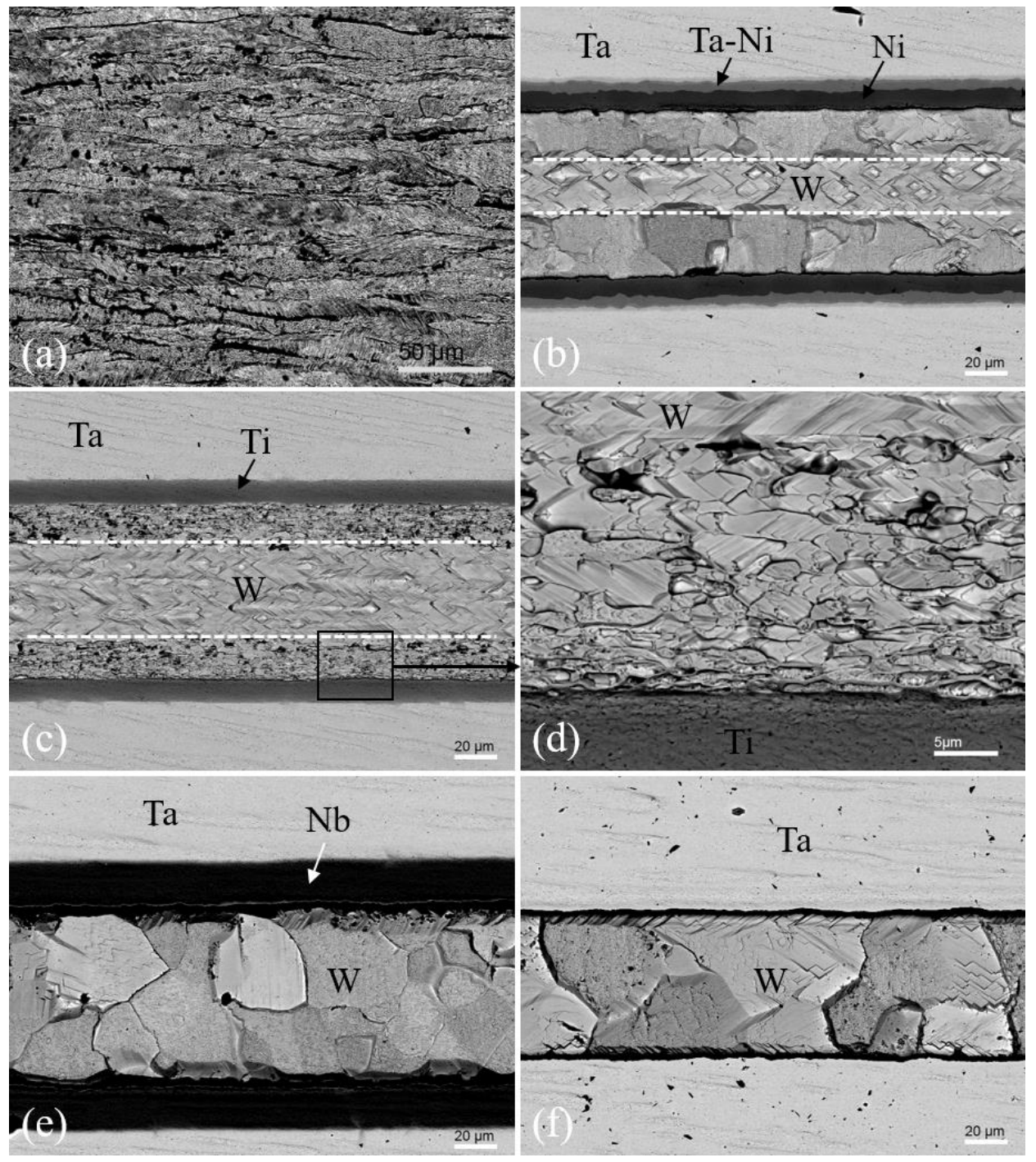

Figure 10. The BSE images of $\mathrm{W}$ grain with the effect of different transition layers, (a) the original $\mathrm{W}$ grain before SPS, (b) W/Ni/Ta, (c,d) W/Ti/Ta, (e) W/Nb/Ta, (f) W/Ta. 


\subsection{Elastic Modulus of W-Ta Laminated Composites}

The prediction of equivalent elastic properties of composite materials is one of the classical problems in micromechanics [28]. Voigt [29] proposed the effective elastic modulus of the composite as

$$
E_{e f f}=E_{1} v_{1}+E_{2} v_{2}
$$

where $E_{\text {eff }}$ is the effective elastic modulus; $E_{1}, E_{2}$ are the elastic modulus of each component; and $v_{1}$, $v_{2}$ are volume fractions of each component. This mixing rule is for the iso-strain state. This model is called the parallel model as it assumes the constituents of a composite to be in parallel arrangement subjected to the same strain. It is the weighted average of the elastic parameters of the two components according to the volume fraction [30]. In this paper, we use the Voigt prediction to predict the Young modulus, shear modulus of W-Ta laminated composites, and compare them with the experimental results. As the existence of transition layer, there are three components of $\mathrm{W}$-Ta laminated composites. Therefore, Equation (2) is extended to obtain Equation (3):

$$
E_{\text {eff }}=E_{1} v_{1}+E_{2} v_{2}+E_{3} v_{3}
$$

In Equation (3), $v_{1}+v_{2}+v_{3}=1$. According to $E=2 G(1+v)$, in which, $G$ is shear modulus, $v$ is the Poisson's ratio, we can get Equaiton (4):

$$
G_{e f f}=G_{1} v_{1}+G_{2} v_{2}+G_{3} v_{3}
$$

Table 4 are the Young's modulus, Poisson's ratio and shear modulus of all metals. According to Equations (3) and (4), Table 4, Figures 3 and 7, we can get simple estimated values and experimental values of W-Ta laminated composites, which are shown in Table 5. We can find that there is a big deviation between the Voigt prediction $E_{\text {eff }}, G_{\text {eff }}$ values and experimental $E_{\text {exp }}, G_{\text {exp }}$ values. Especially the Voigt prediction $E_{\text {eff }}$ values of W/Ni/Ta, W/Ti/Ta and the $G_{\text {eff }}$ values of W/Ta, W/Ni/Ta, W/Nb/Ta. There are two main reasons. On the one hand, the Voigt model is too simple to predict the elastic modulus of laminated composite. On the other hand, the effect of interface and element diffusion can not be ignored.

Table 4. The Young modulus, Poisson's ratio, and shear modulus of all metals.

\begin{tabular}{cccc}
\hline Metals & Young Modulus (GPa) & Poisson's Ratio: $\boldsymbol{v}$ & Shear Modulus (GPa) \\
\hline $\mathrm{W}$ & 406 & 0.28 & 159 \\
$\mathrm{Ta}$ & 186 & 0.35 & 69 \\
$\mathrm{Ni}$ & 214 & 0.31 & 82 \\
$\mathrm{Ti}$ & 114 & 0.35 & 42 \\
$\mathrm{Nb}$ & 105 & 0.35 & 39 \\
$\mathrm{Mo}$ & 329 & 0.31 & 126 \\
\hline
\end{tabular}

\begin{tabular}{|c|c|c|c|c|c|c|c|}
\hline \multirow{2}{*}{ Composite } & \multirow{2}{*}{ Volume Fraction } & \multicolumn{4}{|c|}{ Voigt Prediction } & \multicolumn{2}{|c|}{ Experimental } \\
\hline & & $E_{e f f}(\mathrm{GPa})$ & Deviation (\%) & $G_{e f f}(\mathrm{GPa})$ & Deviation (\%) & $E_{\text {exp }}(\mathrm{GPa})$ & $G_{\exp }(\mathrm{GPa})$ \\
\hline $\mathrm{W} / \mathrm{Ta}$ & W:0.467, Тa:0.533 & 289 & +9.1 & 111 & -18.9 & 265 & 137 \\
\hline $\mathrm{W} / \mathrm{Ti} / \mathrm{Ta}$ & W:0.423, Ta:0.493, Ni:0.084 & 273 & +13.8 & 104 & -5.4 & 240 & 110 \\
\hline $\mathrm{W} / \mathrm{Nb} / \mathrm{Ta}$ & W:0.371, Ta:0.444, Nb:0.185 & 253 & -6.6 & 97 & -18.5 & 271 & 119 \\
\hline $\mathrm{W} / \mathrm{Mo} / \mathrm{Ta}$ & W:0.405, Ta:0.473, Mo:0.122 & 293 & -7.0 & 112 & +1.8 & 315 & 110 \\
\hline
\end{tabular}

Table 5. The Voigt prediction $E_{V p}, G_{V p}$ values and experimental $E_{\text {exp }}, G_{\text {exp }}$ values of the Young modulus and shear modulus.

\section{Conclusions}

In this work, the effects of $\mathrm{Ni}, \mathrm{Ti}, \mathrm{Mo}$, and $\mathrm{Nb}$ transition layers on the properties of $\mathrm{W}$-Ta laminated composite were studied. The following conclusions are drawn. 
$\mathrm{Ni}, \mathrm{Ti}$, and Mo are not suitable for the transition layer of $\mathrm{W}$-Ta laminated composite. The diffusion of $\mathrm{Ni}$ and Ti elements has a bad effect on the matrix and deteriorates the properties of laminated composite. The bonding between Mo transition layer and matrix is poor. W/Mo interface is easy to peel off. Under current preparation conditions, $\mathrm{Nb}$ is the most suitable transition layer for $\mathrm{W}-\mathrm{Ta}$ laminated composite. The tensile and three-point bending tests of $\mathrm{W} / \mathrm{Nb} / \mathrm{Ta}$ both show good toughness. The interface of the composite is greatly strengthened by the reaction layer formed between $\mathrm{Nb}$ and matrix material. Moreover, the introduction of niobium has no bad influence on the composite matrix and further increases the number of interfaces. The $\mathrm{W} / \mathrm{Nb} / \mathrm{Ta}$ laminated composite prepared in this work can effectively solve the problem of tungsten brittleness. It is expected to promote the application of tungsten composite materials. In addition, the Voigt model was used to predict the elastic modulus of W-Ta laminated composites and compared with the experimental results. It is found that the Voigt model cannot predict the elastic modulus of metal laminated composite very well. In the prediction of the elastic modulus of laminated composites, the effect of interface, and element diffusion cannot be ignored.

Author Contributions: Thanks to G.X. for his help in this research experiment, Z.Y. for investigation and to J.S. for his guidance in this research. All authors have read and agreed to the published version of the manuscript.

Funding: This research work is supported by Natural Science Foundation of China Program (51571095).

Acknowledgments: Z.Y. is the main contributor of this research work, including the conduct of the experiment, data collection and analysis, and the writing of the manuscript; Thanks to G.X. for his help in this research experiment, and to J.S. for his guidance in this research. All authors have read and agreed to the published version of the manuscript.

Conflicts of Interest: The authors declare no conflict of interest, or in the decision to publish the results.

\section{References}

1. Zinkle, S.J.; Möslang, A.; Muroga, T.; Tanigawa, H. Multimodal options for materials research to advance the basis for fusion energy in the ITER era. Nucl. Fusion 2013, 53, 104024. [CrossRef]

2. Wurster, S.; Baluc, N.; Battabyal, M.; Crosby, T.; Du, J.; García, T.P.; Hasegawa, A.; Hoffmann, A.; Kimura, A.; Kurishita, H.; et al. Recent progress in R\&D on tungsten alloys for divertor structural and plasma facing materials. J. Nucl. Mater. 2013, 442, S181-S189. [CrossRef]

3. Iveković, A.; Omidvari, N.; Vrancken, B.; Lietaert, K.; Thijs, L.; Vanmeensel, K.; Vleugels, J.; Kruth, J.-P. Selective laser melting of tungsten and tungsten alloys. Int. J. Refract. Met. Hard Mater. 2018, 72, 27-32. [CrossRef]

4. Lassner, E.; Schubert, W.-D. Tungsten; Kluwer Academic/Plenum Publishers: New York, NY, USA, 1999.

5. Ren, C.; Fang, Z.Z.; Koopman, M.; Butler, B.; Paramore, J.; Middlemas, S. Methods for improving ductility of tungsten-A review. Int. J. Refract. Met. Hard Mater. 2018, 75, 170-183. [CrossRef]

6. Li, H.; Wurster, S.; Motz, C.; Romaner, L.; Ambrosch-Draxl, C.; Pippan, R. Dislocation-core symmetry and slip planes in tungsten alloys: $\mathrm{Ab}$ initio calculations and micro cantilever bending experiments. Acta Mater. 2020, 60, 748-758. [CrossRef]

7. Hirsch, P. Comment. In Proceedings of the 5th International Conference on Crystallography \& Novel Materials, Helsinki, Finland, 25-26 November 2019; Cambridge University: Cambridge, UK, 1960; p. 139.

8. Groger, A.; Vitek, V. Multiscale modeling of plastic deformation of molybdenum and tungsten: I. Atomistic studies of the core structure and glide of $1 / 2<111>$ screw dislocations at 0 K. Acta Mater. 2008, 56, 5401-5411. [CrossRef]

9. Bonk, S.; Reiser, J.; Hoffmann, J.; Hoffmann, A. Cold rolled tungsten (W) plates and foils: Evolution of the microstructure. Int. J. Refract. Met. Hard Mater. 2016, 60, 92-98. [CrossRef]

10. Geach, G.; Hughes, J. The Alloys of Rhenium with Molybdenum or with Tungsten and Having Good High Temperature Properties, Plansee Proceedings 1955, Sintered High-temperature and Corrosion-resistant Materials. In Proceedings of the Second Plansee Seminar, Reutte, Austria, 19-23 June 1955; pp. 245-253.

11. Wurster, S.; Gludovatz, B.; Hoffmann, A.; Pippan, R. Fracture behavior of tungsten-vanadium and tungsten-tantalum alloys and composites. J. Nucl. Mater. 2011, 413, 166-176. [CrossRef] 
12. Rieth, M.; Reister, J.; Dafferner, B.; Baumgärtner, S. Michael Rieth Karlsruhe Institute of Technology Institute for Applied Materials P.O. Box Karlsruhe Germany The Impact of Refractory Material Properties on the Helium Cooled Divertor Design. Fusion Sci. Technol. 2012, 61, 381-384. [CrossRef]

13. Aguirre, M.V.; Martin, A.; Pastor, J.Y.; Llorca, J.; Monge, M.; Pareja, R. Mechanical Behavior of W-Y2O3 and W-Ti Alloys from $25^{\circ} \mathrm{C}$ to $1000{ }^{\circ} \mathrm{C}$. Met. Mater. Trans. A 2009, 40, 2283-2290. [CrossRef]

14. Yan, Q.; Zhang, X.; Wang, T.; Yang, C.; Ge, C. Effect of hot working process on the mechanical properties of tungsten materials. J. Nucl. Mater. 2013, 442, S233-S236. [CrossRef]

15. Battabyal, M.; Schäublin, R.; Spätig, P.; Baluc, N. W-2wt.\%Y2O3 composite: Microstructure and mechanical properties. Mater. Sci. Eng. A 2012, 538, 53-57. [CrossRef]

16. Kurishita, H.; Arakawa, H.; Matsuo, S.; Sakamoto, T.; Kobayashi, S.; Nakai, K.; Pintsuk, G.; Linke, J.; Tsurekawa, S.; Yardley, V.; et al. Development of Nanostructured Tungsten Based Materials Resistant to Recrystallization and/or Radiation Induced Embrittlement. Mater. Trans. 2013, 54, 456-465. [CrossRef]

17. Wei, Q.; Jiao, T.; Ramesh, K.T.; Ma, E.; Kecskes, L.; Magness, L.; Dowding, R.; Kazykhanov, V.; Valiev, R. Mechanical behavior and dynamic failure of high-strength ultrafine grained tungsten under uniaxial compression. Acta Mater. 2005, 54, 77-87. [CrossRef]

18. Shen, T.; Dai, Y.; Lee, Y. Microstructure and tensile properties of tungsten at elevated temperatures. J. Nucl. Mater. 2016, 468, 348-354. [CrossRef]

19. Faleschini, M.; Kreuzer, H.; Kiener, D.; Pippan, R. Fracture toughness investigations of tungsten alloys and SPD tungsten alloys. J. Nucl. Mater. 2007, 367, 800-805. [CrossRef]

20. Reiser, J.; Rieth, M.; Dafferner, B.; Hoffmann, A.; Yi, X.; Armstrong, D.E.J. Tungsten foil laminate for structural divertor applications-Analyses and characterisation of tungsten foil. J. Nucl. Mater. 2012, 424, 197-203. [CrossRef]

21. Reiser, J.; Garrison, L.; Greuner, H.; Hoffmann, J.; Weingärtner, T.; Jäntsch, U.; Klimenkov, M.; Franke, P.; Bonk, S.; Bonnekoh, C.; et al. Ductilisation of tungsten (W): Tungsten laminated composites. Int. J. Refract. Met. Hard Mater. 2017, 69, 66-109. [CrossRef]

22. Terentyev, D.; Xiao, X.; Dubinko, A.; Bakaeva, A.; Duan, H. Dislocation-mediated strain hardening in tungsten: Thermo-mechanical plasticity theory and experimental validation. J. Mech. Phys. Solids 2015, 85, 1-15. [CrossRef]

23. Du, J.; You, J.H.; Hoschen, T. Thermal stability of the engineered interfaces in W-f/W composites. J. Mater. Sci. 2012, 47, 4706-4715. [CrossRef]

24. Reiser, J.; Franke, P.; Weingärtner, T.; Hoffmann, J.; Hoffmann, A.; Rieth, M. Tungsten laminates made of ultrafine-grained (UFG) tungsten foil-Ageing of tungsten-titanium (W-Ti) laminates. Int. J. Refract. Met. Hard Mater. 2015, 51, 264-274. [CrossRef]

25. Reiser, J.; Rieth, M.; Moslang, A.; Dafferner, B.; Hoffmann, J.; Mrotzek, T.; Hoffmann, A.; Armstrong, D.E.J.; Yi, X. Tungsten foil laminate for structural divertor applications-Joining of tungsten foils. J. Nucl. Mater. 2013, 5, 47-55. [CrossRef]

26. Zhang, Y.; Ouyang, T.; Liu, D.; Wang, Y.; Du, J.; Zhang, C.; Feng, S.; Suo, J. Effect of thickness ratio on toughening mechanisms of Ta/W multilayers. J. Alloys Compd. 2016, 666, 30-37. [CrossRef]

27. Zhang, Y.; Xu, G.; Wang, Y.; Zhang, C.; Feng, S.; Suo, J. Mechanical properties study of W/TiN/Ta system multilayers. J. Alloys Compd. 2017, 725, 283-290. [CrossRef]

28. Wang, H.; Li, Q. Prediction of elastic modulus and Poisson's ratio for unsaturated concrete. Solids Struct 2007, 44, 1370-1379. [CrossRef]

29. Vogit, W. Ueber die Beziehung zwischen den beiden Elasticitätsconstanten isotroper Körper. Annalen Physik 1889, 274, 573-587. [CrossRef]

30. Liu, P.; Wan, Z. Modified method for the prediction of effective elastic modulus of composite materials. J. Yangzhou Univ. Nat. Sci. Ed. 2007, 10,1.

(C) 2020 by the authors. Licensee MDPI, Basel, Switzerland. This article is an open access article distributed under the terms and conditions of the Creative Commons Attribution (CC BY) license (http://creativecommons.org/licenses/by/4.0/). 